\title{
Las exigencias de la Cooperación: un imperativo ético
}

\author{
Martín Hurtado, María Daniela \\ Universidad de La Laguna, Santa Cruz de Tenerife, España \\ mdanielamartinh@gmail.com
}

\section{Resumen}

Dentro de esta globalización post moderna, donde las tecnologías de la comunicación han difuminado el concepto de distancia y tiempo, y las fórmulas de vida aparecen en anuncios de autopistas, el concepto de «cooperación» ha adquirido el carácter de principio y, por lo tanto, la apariencia de inamovilidad en significado. Sin embargo, las modas discursivas se han alimentado del interés particular y han logrado dar valor a la cooperación, alejándola muchas veces de su función solidaria y propulsora de las mejoras sociales. ¿Qué es cooperación?, ¿A qué valores responde? ¿Está sujeto a servidumbres?

La cooperación es un fenómeno que puede estudiarse desde diversas áreas del conocimiento, siendo enfocado desde el punto de vista jurídico, sociológico, político y económico, desde el punto de vista de las relaciones internacionales y dentro de las políticas internas de estados federales y estados autonómicos.

La cuestión principal de esta comunicación será el entender cómo se construye y se define la cooperación al crear relación con otro y ver el papel que adquieren los elementos básicos de la misma: donante(s), transmisión y receptor. La trascendencia e intencionalidad de la cooperación podrá determinar su construcción y crear el marco que en papel se traduce en expresiones constituidas, y en práctica en vidas incluidas, o no, al mundo de las posibilidades.

Cooperación y educación se unen en ideales de equidad, justicia e inclusión social, más sin embargo, habrá que estar atentos a posibles deformaciones de la intención, y si sobre la mesa de negociación se presentan intereses coordinados o disfrazados porque, en cooperación, no debe haber ni competencia, ni ganador, ni debería tratarse de desarrollistas o economicistas, sino solidaridad compartida, equipo, mundo.

\section{Abstract}

Cooperation demands: an ethical imperative.

In this post-modern globalization, where communication technology has blurred the idea of distance and time, and ways of living appears on slogans, the concept of «cooperation» presents itself with the nature of a principle. A principle brings a «one way» interpretation, and so in this case, the idea of solidarity to achieve social improvements. Therefore, political conflicts, ideological confusions, and the increasingly weak economies have turned out in social crisis and have been fueled «cooperation policies» by particular interest and values. What is cooperation? What values does it respond to?

This essay is focus on understand how de term «cooperation» is built and defined. The intentionality in creating relations and producing interactions for cooperation is been a point of study.

Equity, justice and social inclusion are ideals of cooperation -as a way of international relationship and education -as the way to transform realities-, however, we must distinguish possibles distortions of objectives, because in Cooperation there should not be neither competition, nor winner, but shared solidarity, teamwork and worldview for peace and life.

Palabras clave: cooperación, ética, terminología, desarrollo, educación.

Keywords: cooperation, ethics, terminology, development, education.

\section{LA VALORACIÓN INTRÍNSECA QUE GENERA EL FENÓMENO DE LA COOPERACIÓN}

La creación de modelos de vida "perfectos» se ha convertido en la quasitarea de todas las ramas de las ciencias sociales. Desde los puntos más científico-fácticos, más analítico-estadísticos, o más filosóficos-teóricos se han estudiado cuales serían los elementos que permitirían que las personas pudieran alcanzar, por fin, aquello que según el derecho es innato, y según la realidad parece condicionado: la dignidad. El estudio sistemático de la acción humana, del funcionamiento social, de la diversidad cultural, de las respuestas al medio y la utilización de los recursos que este ofrece nos ha 
llevado a una conclusión, que dentro de su indeterminación, resalta el aspecto más importante de nuestros sistemas sociales: la variedad.

Somos muchos los que habitamos el planeta, con muchas verdades, visiones, perspectivas, con muchas realidades distintas. Sabemos que somos muchos, que somos diferentes pero que nuestra condición humana, y no solo nuestros intentos de estructuración social, nos hace iguales. Sin embargo, y tras el gran desarrollo tecnológico que se ha alcanzado en las últimas décadas, podemos seguir afirmando las palabras de Toledo Padrón $(1996,79)$.

...en la actualidad ni los estados, ni los organismos internacionales, ni la opinión pública, ni las personas ignoran que una gran parte de los habitantes del globo son poco afortunados: no tienen dónde guarecerse, su alimentación es deficiente, su salud es mala, no saben leer ni escribir, carecen de trabajo y sus expectativas de una vida mejor son inciertas.

Estas realidades de marginalidad e inseguridad alrededor del ser humano fueron las que motivaron a la creación del campo de las Relaciones Internacionales, tal y como desarrolla Barbé Izuel (2007), solo que el impulso no fue el hambre o la pobreza que se asocia a territorios mal gestionados o subdesarrollados, sino a las causadas por las guerras del mundo industrializado. El horror, el miedo y la incertidumbre que se vivió luego de la Primera Guerra Mundial, marcó la dinámica que asumirían los países ahora considerados desarrollados en torno a la creación de una red de Estados que fortaleciera los principios de soberanía, los valores de libertad, y crearan, entre otras cosas, la idea de cooperación.

Hasta el momento, la estructura internacional se había desarrollado como una configuración de poder, una realidad social basada en el conflicto y en su correlacionada incompatibilidad de intereses; ahora sin embargo a las ideas de dominación se le fijaron pautas para la coordinación de acciones e intereses, los cuales sería satisfechos de manera conjunta y solidaria. Aun así, el concepto de «mutua satisfacción» quedo encerrado en las mismas consideraciones anteriores a las desgracias de las guerras mundiales, las antinomias de las regiones del Norte y del Sur se mantuvieron, así como las valoraciones que se refieren al primer y tercer mundo, al mundo industrializado y el subdesarrollado.

Es así como la Cooperación Internacional se nutrió de ideas de solidaridad internacional, de interés mutuo, consenso de metas y equidad, creando espacios para las participaciones de cooperación de país a país, o las que funcionaban a través de Organizaciones Internacionales que intentaban crear condiciones de estabilidad y bienestar - tal y como promulgaba la Carta a las Naciones Unidas de 1945 -, logrando que se le adjudicara de manera casi generalizada la idea de ayuda y el carácter de principio. La cuestión con los principios es que denotan la idea de ser inamovibles e incuestionables, de ser buenos y deseables solo por el hecho de ser; pero, dentro de este marco conceptual, el aceptar que cooperar es ayudar, y que igualmente deben mantenerse las estructuras tradicionales dentro de la cooperación internacional - donante y beneficiado -, nos hace preguntarnos el cómo se determina el rol de receptor del beneficio, y a que intereses se estarán respondiendo con estas interacciones.

Todo lo anterior nos lleva a pensar que ante la necesidad de crear espacios para la relación entre naciones, - y que de la unión de estas se favoreciera al alcance de desarrollo equilibrado y progreso social -, nace la ciencia de las Relaciones Internacionales y con ella la Cooperación Internacional, buscando que de su actividad se desprendan resultados equitativos sin antes generar un cambio de paradigma en relación a las ideas de dominación y de jerarquía de los Estados. Actualmente, sin embargo, se nos plantea la cuestión de hablar de verdadera coordinación o de conflicto de intereses y de una posible confusión terminológica e ideológica en relación con la cooperación.

\section{LA JUSTIFICACIÓN DE LA COOPERACIÓN: CONDICIONALIDAD IMPERANTE}

A lo largo de la historia y en base a las necesidades de la época y a las construcciones sociales generadas en respuesta, se ha ido creando un Sistema de Cooperación Internacional, con valores y principios específicos.

En la década de los 50 y 60 tras la finalización de la Segunda Guerra Mundial, la puesta en papel de los derechos del ser humano, y el intento de alcanzar una nueva estabilidad mundial al margen de las nuevas amenazas bélicas; se volvieron a reconocer las realidades que respondían de manera exi- 
tosa a los ideales de lo desarrollado, y aquellas que, por el contrario, no respondían. En base a esto se empiezan a generar las Teorías Desarrollistas que tenían como objeto el establecer parámetros e indicadores que establecieran el nivel de desarrollo de las naciones, y así poder generar políticas en respuesta. A través de estas políticas se buscaría satisfacer las necesidades generadas de la pobreza, fomentar el desarrollo rural y agrario, generar empleos y mejorar las políticas distributivas, cuestiones a las que se sumaron las políticas de Cooperación. Este enfoque continuó durante la década de los 70 , afinando su acción a la satisfacción de las necesidades básicas de toda la población mundial, pero manteniendo la idea del desarrollo como prioridad, y a la copia de los modelos y la consecución de parámetros establecidos como metodología para alcanzarlo.

Esta metodología era considerada única y lineal, que a través de procesos de asimilación buscaban la trasposición y reproducción un modelo cultural, económico, social, así como la transmisión de los valores, las normas y la concepción de la realidad específica, que permitiría la traducción de una realidad subdesarrollada, a una realidad de desarrollo óptimo.

En la década de los 80 , sin embargo, los sucesos mundiales llevaron a que se generara la necesidad de la liberación de los mercados mundiales, y por lo tanto la visión economicista inundó el pensamiento de la cooperación internacional que lo tomo como base y condición para generar acuerdos, cambiando así el enfoque desarrollista aplicado hasta el momento. Esta época remarcó la importancia del cumplimiento de ciertas condiciones para entrar en las dinámicas de la cooperación internacional, y por lo tanto remarcaron la fuerza y los intereses del país donante, y la posición de subordinación del país beneficiario.

Con lo anterior expuesto no se intenta enjuiciar el derecho que tiene toda nación de establecer los criterios que describan su acción exterior, ya que los mismos forman parte de aquello que le es propio y que debe ser protegido en base a que se desprende de los principios de sus ordenamientos y principios jurídicos, ya que tal y como dice Ayllón Pino (2007) «Cada «década del desarrollo» ha puesto el énfasis en un aspecto que los países donantes o la instituciones multilaterales, principalmente, juzgaban representar la varita mágica para solucionar los problemas de subdesarrollo del Tercer Mundo». Sin embargo, es el punto de introducción a los argumentos que desarrollan las teorías y autores de la Cooperación Internacional que vuelven a remarcar dos visiones o líneas distintas: la cooperación inclinada a los intereses del donante, o la cooperación como una respuesta moral y ética a las problemáticas mundiales.

Ayllón Pino desarrolla los distintos enfoques teóricos que entienden alguna de estas dos visiones, y cuestiona la motivación de los Estados a adentrarse en las políticas de cooperación, y si la misma es realmente eficaz a la hora de alcanzar su objetivo solidario:

...la propia eficacia de la cooperación internacional, en la medida en que, después de cincuenta años y de miles de millones de dólares, la pobreza persiste en el mundo. En consecuencia, argumentarán algunos, la cooperación es ineficaz y, peor aún, en muchas ocasiones se ha convertido en una trampa que contribuye a perpetuar la miseria y la dependencia pues transforma a los países subdesarrollados que dependen de la ayuda en Estados pasivos, con ciudadanos que no encuentran incentivos para emprender, o generar mecanismos autónomos para escapar de la pobreza. (Ayllón Pino, 2007).

Muchos de los autores que defienden el acento de la cooperación en el interés del país donante, defienden la prioridad de la seguridad estatal, así como la importancia de asegurar el crecimiento en prestigio, influencia política, o en inversiones. Por el contrario, otros enfoques entienden que la cooperación y el establecimiento de condiciones sin medida puede verse como una acción intervencionista que reforzaría los patrones de desigualdad, y perpetuaría la dependencia de los mismos.

El aprovechamiento de los recursos del llamado tercer mundo, de los naturales y de los humanos, siempre ha sido interés para la industria y el mundo del comercio. Con la intención de establecer un contrapunto a este aprovechamiento y abuso de intereses por parte de los países donantes, se creó el sistema triangular de cooperación, una alternativa a las condicionalidades impuestas por un único donante y que genera una relación entre el país financiador, el país ejecutor y el país beneficiario.

De igual manera, la década de los 90 y el desarrollo actual de las prácticas de Cooperación han desarrollado un modelo más inclusivo, con la toma en consideración del Índice de Desarrollo Humano como criterio de desarrollo y el esfuerzo en permitir la apropiación de los grupos implicados en el proceso, democratizándolo. Aun así, las palabras de Vázquez Montalbán deben mantenerse como un recordatorio fijo «si hay países subdesarrollados, es porque hay países subdesarrollantes». 


\section{DEBER SER HORIZONTAL}

La determinación de los valores que son asociados al término de cooperación dentro del mundo educativo tiene relevancia al concientizar sobre la acción real que se quiere ejercer en el mundo internacional, el cómo y por qué cooperar incluidos en la idea de equidad, deberá llevarnos a la idea verdadera de la cooperación justa, inclusiva, solidaria y mutua.

La globalización y las tecnologías de la comunicación difuminan cada vez con mayor rapidez las fronteras nacionales, y se hace una necesidad el crear marcos normativos e ideas concientizadas alrededor de la idea de las Comunidades Internacionales. La interdependencia que se ha generado hasta ahora y que se construye con mayor fuerza cada vez nos indica que se necesita de una participación más igualitaria en la red internacional, y que debe crearse un marco estratégico para la acción futura, y que éste no debe independizarse de la acción de la Cooperación.

... esta macrosociedad es una sociedad global de referencia (sociedad de sociedades)... posee una importante dimensión relacional en la medida en que sus miembros mantienen unas relaciones mutuas intensas y perdurables en el tiempo, no esporádicas y ocasionales, mostrando una disposición... a compartir un orden común aún cuando aspiren a modificarlo pacifica o violentamente» (Toledo Padrón, 1996).

La cooperación debe encontrar su espacio en el mundo actual, y reconciliarse con su naturaleza solidaria, porque a pesar de que esta nace de situaciones de discordia y de realidades problemáticas o de necesidad, la imposibilidad de alcanzar objetivos específicos, o hacer frente a estos problemas es solo la mitad de su contenido; la otra mitad debe ser la búsqueda de la justicia, y el comprender que el ser humano, su vida y su dignidad no deben quedar a sujetos a condicionalidades o intereses políticos.

Hay que ser cuidadosos, entonces, al hablar de cooperación, y entender a qué interés y valores responde. La construcción deberá ser paulatina, crear conexión antes de hablar de vínculos, crear relaciones antes de proponer ayudas, y lograr entender realidades, antes de inmersionarse a cooperar en lo que es ajeno.

\section{REFERENCIAS BIBLIOGRÁFICAS}

Ayllón Pino, B. (2007). La Cooperación Internacional para el Desarrollo: fundamentos y justificaciones en la perspectiva de la Teoría de las Relaciones Internacionales. Carta Internacional de la Asociación Brasilera de las Relaciones Internacionales. 2(2) 25-40.

Barbé Izuel, E. (2007). Relaciones Internacionales. $3^{\circ}$ Edición. Madrid: Tecnos.

Calabuig Tormo, C. y Gómez-Torres, M. (2010). La Cooperación Internacional para el Desarrollo. Valencia. Editorial de la Universitat Politècnica de València.

Martín Beristain, C. (1999). Reconstruir el tejido social. Un enfoque crítico de la ayuda humanitaria. Barcelona: Icaria.

Toledo Padrón, Z. (1996). Educación, Desarrollo y Planificación Educativa según Propuestas de la Unesco (1960-1990). Tesis Doctoral. La Laguna. Universidad de La Laguna. 